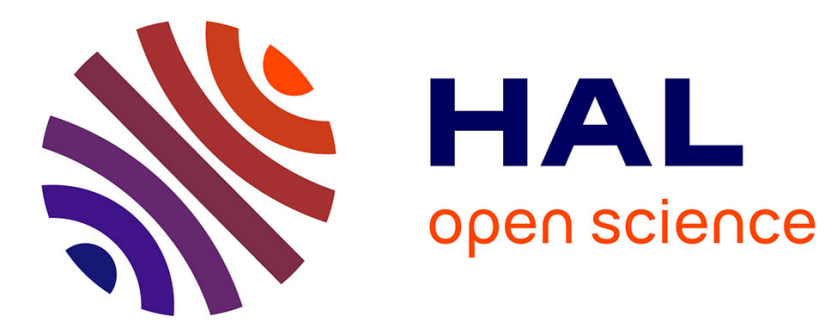

\title{
Interfacing information and prosody
}

Viviane Deprez, Kristen Syrett, Shigeto Kawahara

\section{To cite this version:}

Viviane Deprez, Kristen Syrett, Shigeto Kawahara. Interfacing information and prosody. Irene Franco, Sara Lusini \& Andrés Saab. Romance languages and Linguistic Theory, John Benjamins Publishing Company, pp.135-154, 2010. hal-00927013

\section{HAL Id: hal-00927013 https://hal.science/hal-00927013}

Submitted on 10 Jan 2014

HAL is a multi-disciplinary open access archive for the deposit and dissemination of scientific research documents, whether they are published or not. The documents may come from teaching and research institutions in France or abroad, or from public or private research centers.
L'archive ouverte pluridisciplinaire HAL, est destinée au dépôt et à la diffusion de documents scientifiques de niveau recherche, publiés ou non, émanant des établissements d'enseignement et de recherche français ou étrangers, des laboratoires publics ou privés. 


\title{
Interfacing information and prosody
}

\section{French wh-in-situ questions}

\author{
Viviane Déprez ${ }^{\star}$, Kristen Syrett \& Shigeto Kawahara \\ ${ }^{\star}$ Laboratoire sur le Langage, le Cerveau et la Cognition (L2C2-CNRS) / Rutgers \\ University
}

\begin{abstract}
We present experimental evidence bearing on Cheng and Rooryck's (2000) proposal that French wh-in-situ questions are licensed by an intonational morpheme also present in yes-no questions and their claim that such questions are ungrammatical without a rising contour. While most participants produced a rising contour, not all did; when they did, the slope was not as steep as in yes-no questions. Our findings support C\&R's proposal, admitting the central role of information structure. We support a view of question formation in French in which information structure, syntax, and prosody form a tight relationship: the shape of the syntactically-designated contour is affected by pragmatic information. We present a theoretical account appealing to movement through givenness-marking that explains the observed pitch compression.
\end{abstract}

Keywords: wh-questions; French interrogatives; prosody; information structure; givenness

\section{Introduction}

French has both moved wh-questions and wh-in-situ questions, as indicated in (1a-b).

(1) a. Elle est allée où en Allemagne? she is.3SG go-PST-F where in Germany 'Where did she go in Germany?'

b. Où est-ce-qu' elle est allée en Allemagne? where QUES she is.3SG go-PST-F in Germany 'Where did she go in Germany?'

In an influential paper that provided an elegant account for wh-in-situ questions in French, Cheng and Rooryk (2000) (henceforth C\&R) claimed that these questions manifest the following properties. (We note here other researchers making similar claims.) 
A. They occur in particular discourse contexts characterized as 'strongly presuppositional', which foster positive expectations and exclude negative answers (Chang 1997);

B. They only occur in root clauses and cannot be embedded (Boeckx 2000; Bošcović 2000);

C. They are sensitive to intervention effects (Boeckx 2000; Bošcović 2000; Zubizarreta 2003);

D. They are syntactically licensed by an intonation morpheme merged in $\mathrm{C}$ that induces an obligatory sentence-final rising intonation contour identical to the one found in purely intonational yes-no questions, such as the one in (2).

\section{(2) Elle est allée en Allemagne? she is.3sg go-PST-F in Germany 'Did she go to Germany?'}

Of these four claims, only $(C)$ remains unchallenged. The discourse and syntactic claims in (A) and (B) have been questioned by attested corpus examples featuring negative answers or embedded instances of in-situ questions (Adli 2006; Hamlaoui 2009; Mathieu 2009). However, the possibility of dialectal distinctions (Zubizarreta 2003) or other semantic nuances (Baunaz \& Patin 2009) still leaves this issue open. C\&R's claim about the obligatory rising intonation morpheme in (D) has been challenged in a number of papers. However, these challenges have relied primarily on informal intuitions (Hamlaoui 2010; Mathieu 2009), and occasionally on previous experimental studies, which were not specifically designed to investigate the prosody of in-situ questions (Delattre 1966; Beyssade et al. 2007; a.o.) and/or omitted important design variables, thereby casting doubts on the solidity of their results (Adli 2006; cf. also Wunderli 1983, 1984). As a consequence, the validity of both C\&R's claims and the objections to them remain controversial.

In this paper, we first summarize the results of an experimental investigation reported on in Déprez, Syrett and Kawahara (2012) (henceforth DS\&K), which specifically targeted the intonation of French wh-in-situ questions, while also taking into account some key aspects of their discourse felicity conditions. We then discuss the impact of these results on the claims in (D), the heart of C\&R's account. Drawing on recent works by Kučerová (2007) and Wagner $(2005,2006)$, we also discuss how a deeper understanding of information structure brings new insights on how pragmatic, prosodic and syntactic factors interact in the licensing of these questions. C\&R have claimed that French wh-in-situ questions are characterized by an obligatory rising contour that is identical to that of yes-no questions. In DS\&K, we address this claim experimentally with a production study of French in-situ questions. In this paper, we rely on these empirical findings to ground a more general, theoretical discussion of the information structure and syntactic licensing of wh-in-situ questions. 
The structure of the paper is as follows. In Section 1, we summarize our experimental findings on the prosody of French wh-in-situ questions. In Section 2, we discuss the discourse conditions that have been found to affect the felicity of these questions. In Section 3, we bring these two strands of research together, reflecting upon how they interact with one another and what role these distinct factors play in licensing these questions. We end with predictions concerning how our findings could play out in the particular theoretical model for question licensing drawn by Richards $(2006,2010)$.

\section{The prosody of French in-situ questions: An experimental investigation}

C\&R proposed that French wh-in-situ questions are syntactically licensed by an abstract intonation morpheme in $\mathrm{C}$. This morpheme plays a role largely identical to the one played by overt question particles in wh-in-situ languages such as Japanese or Korean (Cheng 1997). On this view, wh-in-situ questions - be they apparently optional (French, Portuguese) or more generally obligatory (Chinese, Japanese) - are syntactically licensed in a unified way: through the presence of a specialized complementizer that marks the clause as an interrogative and licenses the in-situ question term.

$C \& R$ claim that the French intonation morpheme is phonetically realized as an obligatory sentence-final rising contour comparable to the one commonly found in purely into national yes-no questions. This proposal makes the following two empirical predictions for the intonation of French wh-in-situ questions. First, they should consistently manifest a detectable sentence-final rising contour. Second, their final rise should be qualitatively identical to the one observed in purely into national yes-no questions. We tested these predictions experimentally in DS\&K, which we briefly review here. (See DS\&K for further details.)

\subsection{Experimental design}

\subsubsection{Participants and procedure}

12 French native speakers (5 F, 7 M; age range: early 20 s - late 50 s) ${ }^{1}$ were recorded in a sound-attenuated booth using a high quality microphone. Stimulus sentences were presented one at a time on a computer screen.

1. Speakers were from French regions, and were second language speakers of English, having been in the States for a time ranging between a few months to several years. Our data revealed no effect of time spend in the United States or region. 


\subsubsection{Stimuli}

The stimuli consisted of seven sentence types: (1) declarative, (2) yes-no question withest-ceque, (3) yes-no question withoutest-ceque in declarativeform, (4) wh-in-situ question (content), (5) wh-in-situ question (echo), (6) moved wh-question with est-ce que, (7) moved wh- question without est-ce que and with subject-auxiliary inversion. The first three served as the baseline of intonation contours, as predictions of a rise or lack of rise were clear. The fourth was our target construction.

Each sentence was preceded by a short context presenting a choice scenario. This setup was intended to make the target sentence felicitous by providing most of the question information content, except for the questioned constituent itself. A sample context with three types of target sentences is given in (3).

(3) Pour participer à un test de psychologie, to participate-INF in a test of psychology

'To participant in a psychology test',

Emma devait placer un rond, un carré ou un triangle Emma must-pst place a circle a square or a triangle 'Emma had to place a circle a square or a triangle'

sur un tableau.

on a board

'on a board.'

Le psychologue a demandé:

the psychologist has ask-PST

'The psychologist asked:'

[Additional sentence for yes-no question only:]

Emma a pris le rond et l'a placé

Emma has take.PST the circle and it has place.PST

sur le tableau.

on the board

'Emma took the circle and placed it on the board.'

a. moved wh- question ( $w h$ - phrase underlined)

Quel élément a-t-elle mis au milieu? which shape has she put-Pst in.the middle 'Which shape did she place in the middle?'

b. wh-in-situ question

Elle a mis quel élément au milieu? she has put-PST which shape in.the middle 'She placed which shape in the middle?'

c. yes-no question

Elle a mis cet élément au milieu? she has put-PST this shape in.the middle 'She placed that shape in the middle?' 
There were five such discourse contexts for each of the seven sentence types, resulting in a total of 35 items. To prevent the sentence-final contour from being merged with the pitch accent on the wh-term, and to prevent potential sentence-final creakiness from disrupting the F0 contour, the in-situ question items were always followed by PPs that were either complements or adjuncts of the verbs as in (3b). Lexical items used sonorants as much as possible to obtain an unperturbed into national contour.

Sentence types were blocked to avoid the influence of minimal pair members on each other (e.g. declaratives never appeared alongside purely into national yes-no questions). Participants were randomly assigned to one of three conditions in a Latin square format. The order of the sentences was randomized within each block per participant. All recordings were inspected for naturalness by native French speakers. See DS\&K for discussion of the naturalness judgment task and additional coding of files.

\subsubsection{Analysis}

Two types of data were collected for analysis: (1) categorical perception of sentencefinal rise/fall and (2) quantitative measure of intonation contour (fundamental frequency, or F0). For the first measure, three research assistants independently coded sound files for rise/fall. These files were then given to two additional coders with little to no knowledge of French for double-blind verification. Agreement between this second group of coders was $90 \%$. All disagreements were resolved by discussion while listening to the files, still blind.

For the second measure, all the target sentences were annotated in Praat (Boersma \& Weenink 1992-2011). Target sentences were divided into 40 windows with equal duration beginning with the onset of the wh-word or corresponding determiner and ending at the termination of the sentence. The average F0 was calculated for each window, allowing us to quantify the sentence-final intonational contour for each sentence. We then performed statistical analyses of these values using R.

\subsection{Results}

Analysis 1 . The percentage of perceived final rise is presented in Figure 1. The three baseline cases patterned as predicted, with declarative sentences manifesting little to no final rise, and yes-no questions showing a final rise in nearly every instance. These differences are significant from each other and from chance level (by proportion and binomial tests). At first glance, the abovechance $(p<.001)$ percentage of sentence-final rise for the target wh-in-situ questions (73.3\%) appears to support C\&R's proposal that this type of question is characterized by a final rise. Yet the difference between this sentence-type 
and each of the two yes-no questions is significant $(p<.001)$. Moreover, the size of the variance observed in the target $w h$-in-situ content questions (represented by the size of the error bar in Figure 1) was greater. We therefore conducted a further analysis.

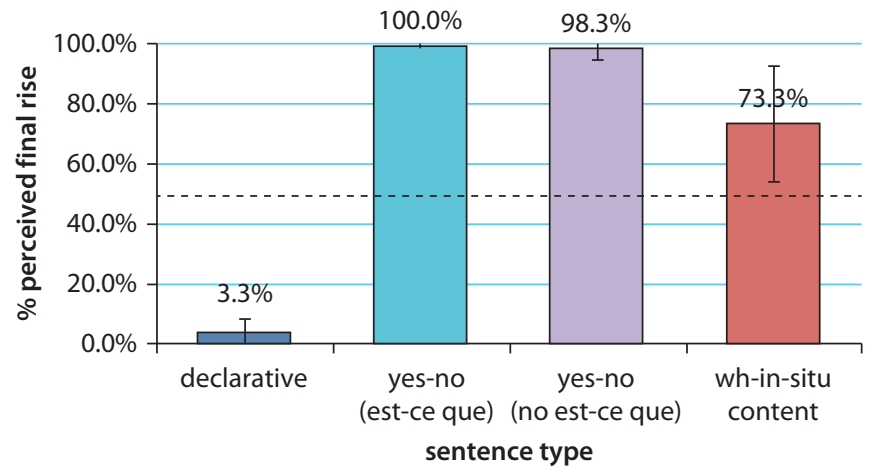

Figure 1. Percentage of perceived final rise for four key sentence types (three baseline sentences and the target $w h$-in-situ content questions). Error bars represent standard error

This follow-up analysis revealed a bimodal distribution of participants for these cases, illustrated in Figure 2. While the majority of participants (Group 2: $\mathrm{N}=9$ ) assigned a final rise to the target $w h$-in-situ content questions, a subset of participants (Group 1: $\mathrm{N}=3$ ) did not. The difference in the percentage of sentence-final rise for these two groups was significant $(p<.01)$. Thus, while these results provide some support on the whole for C\&R's claims about an expected sentence-final rising intonation of wh-in-situ content questions, the difference between the wh-in-situ and the yes-no questions, and the difference between two groups of speakers - both unexpected on C\&R's view - still called for an explanation. For this reason, we turned to an inspection of the intonation contour for two speaker-groups.

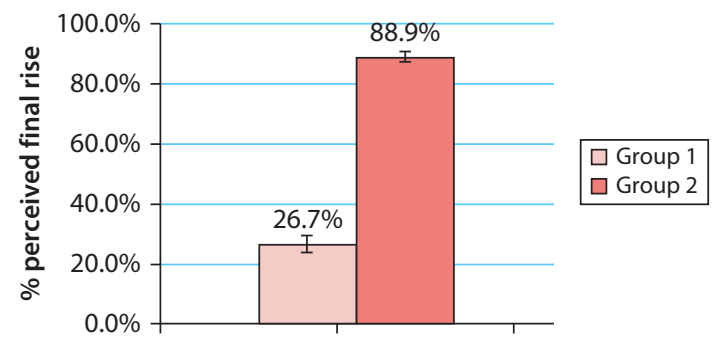

Figure 2. Percentage of perceived final rise for two groups of participants producing wh-insitu content questions 
Analysis 2. In the second analysis, we calculated the F0 values for the individual sentence types from the onset of $w h$-word (or the corresponding determiner) to the end of the sentence. We averaged these values across items and participants, and plotted these for each of the two groups of speakers noted in the rise/fall coding of the first analysis. Figure 3 presents the results of this acoustic analysis.

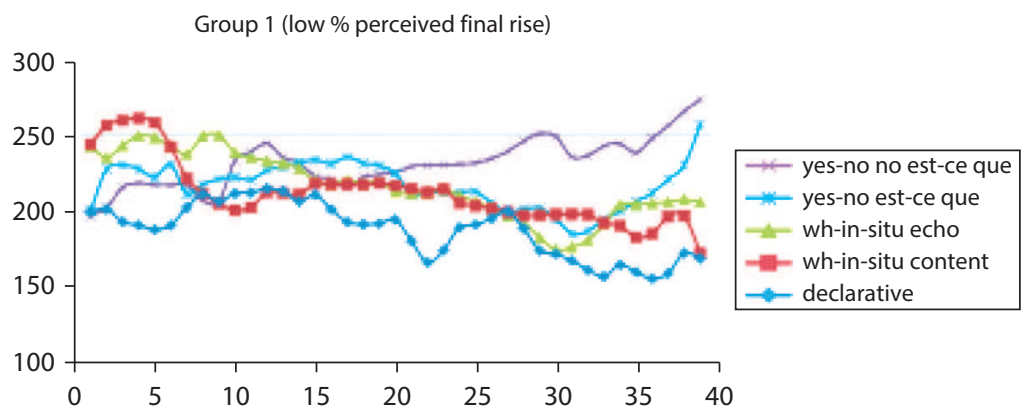

Group 2 (high \% perceived final rise)

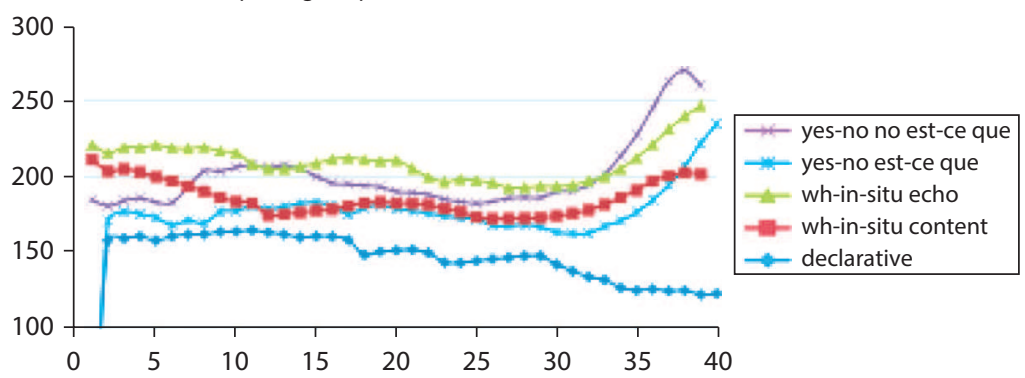

Figure 3. Sentence-final contour for five of the sentences produced by speakers in Groups 1 and 2, averaging over items and speakers

In comparing the graphs, note first that the baseline cases (declaratives and yes-no questions) manifested the expected falling or rising contours respectively for both groups. For the target wh-in-situ content questions, Group 1 (top graph) generally exhibited a fall from a high initial start, somewhat elevated compared to declaratives. By contrast, Group 2 (bottom graph) exhibited a rise, which was somewhat depressed from both yes-no questions and from their echo wh-in-situ counterparts. This finding is unexpected if in-situ questions should obligatorily have the rising contour of yes-no questions, as C\&R claim. (In DS\&K, we also compare the wh-in-situ cases with moved wh- questions, which exhibit no such rise.)

Yet another interesting difference that emerged between the two groups concerned the height of the pitch accent on the $w h$-term. This pitch accent was higher for Group 1 (around 250Hz) than for Group 2 (around 200Hz), and appears to be negatively correlated with the sentence-final rise observed for each of the two 
groups: the higher the pitch accent, the more likely a falling sentence-final contour, and vice versa.

To further investigate this correlation for the wh-in-situ questions, we performed a quantitative comparison of the wh-region with the sentence-final region. We took the maximum $\mathrm{F} 0$ value in the first 10 windows after the onset of the $w h$-item, and the minimum F0 value in the following 10 intervals, and calculated the difference in F0 between the two points. We refer to this value as "Initial Max - Initial Min." We then found the maximum F0 value in the last 5 intervals of the sentence, and calculated the difference between the initial maximal value and the final maximal value. We refer to this value as "Initial Max - Final Max."

We predicted that a large "Initial Max - Initial Min" difference should be positively correlated with a large "Initial Max - Final Max" difference. This correlation, we reasoned, would result from high pitch accenting on the wh-word followed by a depressed rise, a plateau, or even a fall. Likewise, a small or negative "Initial Max - Initial Min" difference should be correlated with a small or a negative "Initial Max - Final Max" difference, indicating the presence of a rise. Indeed, using this analysis we found a significant correlation between the two measures $(r=0.83, p<.001)$. A scatterplot capturing this correlation is in Figure 4. Each dot represents a wh-in-situ question.

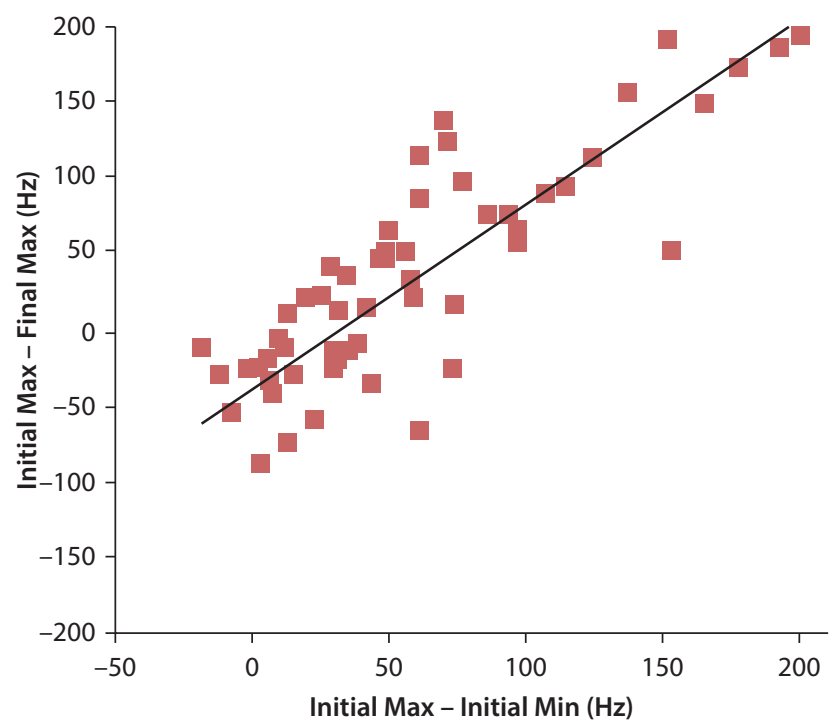

Figure 4. Scatterplot demonstrating a correlation between two difference values for each item, based on maximal and minimal values in the $w h$-region and a maximal value in the sentencefinal region of the wh-in-situ (content) questions 
This pattern indicates that a higher pitch accent on the wh-term is negatively correlated with a final rise for the $w h$-in-situ questions. This connection indicates that instead of being simply optional (as some researchers have claimed), the presence and shape of the rise for the speakers may instead be variable and conditioned by the focus placed on the $w h$-word. The speaker variability we observed between the two groups could well be a matter of how the $\mathrm{H}$ morpheme is phonetically realized (whether on the wh-element or as a sentence-final contour). Alternatively, it could encode a distinction as to how information structure impacts on the realization of the rise: focusing the $w h$-element impacts the final rise by compressing the F0. On either view, our experimental results can be taken to provide nuanced confirmation for C\&R's proposal. Thus, in contrast to earlier objections raised against C\&R's view, we find their claim to not only be tenable, but also compatible with our experimental results, provided that the target morpheme is allowed a variable phonetic realization, influenced by other factors that could manipulate the shape and height of the intonation contour. Granting this possibility, we take time to explore its significance here. But first, we must turn to a discussion of the discourse factors that have been considered essential to the licensing of French wh-in-situ questions.

\section{The information structure of French $w h$-in-situ questions}

In addition to an intonational parallelism, $\mathrm{C} \& \mathrm{R}$ also argued that French wh-in-situ questions and yes-no questions share similar discourse conditions. They claimed that both types of questions require 'strongly presupposed contexts' where the event of the question is already present in the common ground, so that the question requests precisification. They further argued that this shared 'strong presupposition' is characterized by a positive answerhood condition.

For yes-no questions, C\&R noted that in English, there is a difference in answerhood between subject-auxiliary inverted yes-no questions, such as (4a), and purely intonational ones, such as (4b). The former does not presuppose a positive answer, and, accordingly, fails to license continuation sentences such as "I presume" or "I take it." In contrast, such continuations are natural for the latter, indicating, according to $\mathrm{C} \& \mathrm{R}$, that the speaker presupposes a positive answer.

(4) a. Are you cooking tonight \# I assume?

b. You are cooking tonight, I assume?

$\mathrm{C} \& \mathrm{R}$ claim that in English the presupposition of a positive answer is a property of yes-no questions marked by rising intonation without inversion and, hence of the intonation morpheme that characterizes them. They further claim that French 
wh-in-situ questions, which share the intonation morpheme, likewise presuppose positive answers, hence failing to felicitously allow negative answers, as seen in (5).

(5) Marie a acheté quoi? \#Rien.

Marie has bought-PST what nothing

'Marie bought what? \#Nothing.'

The validity of this claim, however, has been questioned in the literature (Adli 2006; Baunaz \& Patin 2009; Boeckx 2000; Starke 2001). First, many speakers do not agree with the assignment of an infelicitous status to (5). Second, examples of negative answers to wh-in-situ questions have been attested in spoken language corpora, as exemplified in (6) (cited in Mathieu 2009): ${ }^{2}$

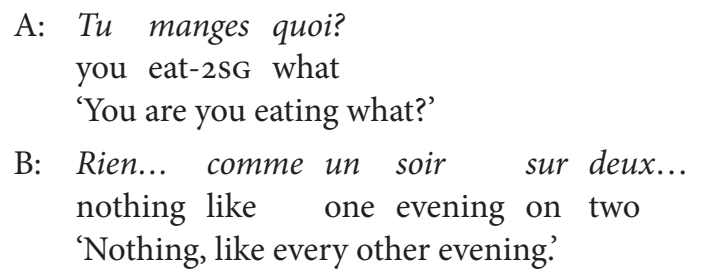

Our research further questions the nature of the link between the rising intonation morpheme and the requirement of a positive answer in general. If the intonation morpheme is implicated not only in wh-in-situ questions, but also in yes-no questions, then one would expect this same property to be associated with both.

However, recall that besides cases of inversion, French has two types of yesno questions: one with est-ce-que, and one with a declarative form. As shown in Figures 1 and 3 above, both types manifest a characteristic sentence-final rising contour, possibly, as C\&R proposed, the result of their intonation morpheme. ${ }^{3}$ And yet, as (7) shows, these questions differ with respect to answerhood requirements. Thus, (7a), like the English (4a) does not allow the continuation, while (7b) does.

(7) a. Est-ceque tu sors ce soir, \# je présume? QUES you go.out-2SG this evening I presume-1SG 'Are you going out tonight, I presume?'

b. Tu sors ce soir, je présume? you go.out-2sG this evening I presume-1sG 'You are going out tonight, I presume?'

2. For some authors the possibility of negative answers may, however, be a matter of dialectal variation (cf. Zubizarreta 2003) and/or depend on the specificity of the wh-term (Baunaz \& Pattin 2009).

3. "It should be noted that est-ce-que and the yes/no intonational morpheme can in fact co-occur" (C\&R 2000:9). 
Thus, a positive answerhood expectation cannot be linked to intonation alone and if as C\&R claim, the intonation morpheme is common to both types of French yes-no questions on the one hand, and to wh-situ questions on the other hand, then this answerhood restriction cannot be a direct discourse consequence of the morpheme's presence.

Revisiting the discourse conditions on wh-in-situ questions, Hamlaoui (2009, 2010) argues that neither 'strong presupposition' nor 'positive answerhood' adequately characterize the contexts in which such questions felicitously occur. She further argues that wh-in-situ and fronted (or moved) wh-questions differ in the information structure of the non-wh portion of the sentence. Specifically, wh-in-situ questions are felicitous "only when the non-wh portion of the question contains no information which is presented as discourse-new [i.e. it is given]" (Hamlaoui 2010:2). The $w h$-item presents the only new information and is focused. By contrast, for fronted wh- questions, the non-wh-portion is typically not given and it consequently belongs to the focus set of the question along with the wh-phrase. Thus, the difference between wh-in-situ and moved wh-cases is what is in the focus set of questions, and whether or not information besides the $w h$-term is in this set.

The notion of givenness that Hamlaoui appeals to (following a number of other researchers) does not require that all parts of the non-wh portion of the question be mentioned in the preceding context or presupposed. Rather, it is sufficient for the context to generate a conversational implicature that can serve as an antecedent to the wh-in-situ question in order for givenness to be satisfied. As Wagner (2006:6) puts it, "Marking a constituent as given requires that an appropriate antecedent is either salient or can be constructed from material salient in the current discourse." Consider the dialogue in (8) from Chang (1997) (which C\&R also cite).

(8) A. C'est l' anniversaire de Pierre la semaine prochaine. it is the birthday of Pierre the week next 'It is Pierre's birthday next week'.

B: Et tu vas lui acheter quoi (comme cadeau)? and you go him-Dat buy-INF what (as gift) 'And what will you buy him (for a gift)?'

There is no salient object in the discourse to which the wh-item refers. There is, rather, an expectation (be it a conversational implicature or presupposition) that people buy presents for other people's birthday. Thus, the non-wh-portion of B's utterance is pragmatically given, allowing the $w h$-element to remain in situ.

For additional support, consider the following example. Imagine that midafternoon, you are hanging out with a couple of friends, to whom you would like to extend an impromptu invitation for dinner the same night. Casually, in the course of the conversation you ask either (9a) or (9b). 

a. Alors, vous faites quoi ce soir?
so you.PL do-PRs.2PL what this evening
'You are doing what tonight?'
b. Alors, qu' est-ceque vous faites ce soir? so what QUES you.PL do-PRS.2PL this evening 'What are you doing tonight?'

There appears to be a difference between (9a) and (9b). While (9a) feels entirely natural, (9b) feels almost nosy. Where could this difference between the two cases come from? Let us venture the following. As in (8), (9a) carries with it a pragmatic implicature or presupposition that your friends are socially active people expected to have evening plans. To convey this implicature allows for an indirect way of checking your friends' availability without sounding like you are probing their personal life. Note that, in this context, you hope that the answer will be negative, so that they can attend dinner. Thus, positive answerhood does not always accompany wh-in-situ questions.

Consistent with this line of argumentation, we would like to claim that our experimental data can be characterized as supporting the role of information structure in the licensing of wh-in-situ and in the variability observed in the intonation contour. Note that allowing the given-new contrast to enter into the picture makes clear predictions for the prosody of these sentences. A common assumption in the literature is that given elements, being in a sense anaphoric or dependent on the preceding discourse, are de-stressed or at least non-prominent (Féry \& Samek-Lodovici 2007; Hamlaoui 2010; Schwarzschild 1999; Williams 1997, among others). The $w h$-item remaining in situ is focused and/or has a discourse new status. Thus, we would predict that the $w h$-phrase should be the most prominent element relative to the rest of the sentence (or at least prominent relative to all non-focused elements).

Indeed, highest prominence of the wh-phrase is at the basis of Hamlaoui's Optimality Theory approach. On this view, we might, then, expect that there would be no sentence-final rise (since all non-wh-elements would be given and de-stressed, and the approach does not assume the presence of an obligatory rise), and therefore that the prosodic contour for French wh-in-situ questions would be distinct from the one predicted by C\&R. Our experimental findings, however, do not entirely support this position, since they demonstrate a strong correlation between wh-in-situ questions and a rising sentence-final contour (with the exception of the pattern instantiated by Group 1). However, we do agree with Hamlaoui about the central role of information structure in the licensing and realization of wh-in-situ questions in French.

Summarizing, then, our experimental findings both support and encourage a revision of both C\&R's and Hamlaoui's claims. On the one hand, we find a rising 
contour, consistent with C\&R's predictions. However, this rise is generally lower than that of yes-no questions (Figure 2) and is variable across speakers. And in some speakers, the rise is diminished or absent, while being accompanied by a pronounced high pitch accent on the wh- word. Our observation that the rise has a depressed and variable realization is in line with Hamlaoui's predictions. Moreover, the positive correlation in Figure 4 between the realization of the final-rise and the pitch accent on the $w h$-item shows that there is a relationship between the two. C\&R's proposal that the rise is introduced by a special morpheme to which the wh-in-situ term is syntactically linked grounds this connection theoretically. We find this connection between syntax and prosody promising (as have others in recent years: e.g. Richards $(2006,2010)$ ), and therefore discuss in more detail its implications in the following section.

\section{Prosody-information structure interface}

In this section we explore a novel analysis of French wh-in-situ questions, drawing on recent proposals concerning the interface between prosody, syntax, and information structure to enlighten our findings and probe the interaction between the role of the discourse context and C\&R's intonation morpheme proposal. We begin with our finding that the intonation contour of wh-in-situ and yes-no questions are both rising, but distinct from each other. One way to account for the distinction between the two is to say that each of these two question types is associated with a distinct intonation morpheme, and that there is therefore no reason to expect the same contour. However, we find this possibility to be unparsimonious and uninteresting from a theoretical perspective, and therefore leave it aside.

Instead, we propose (here and in more detail in DS\&K) that despite differences in their rising contour, these questions do in fact share the same abstract intonation morpheme. The observed distinction is either due to a difference in phonetic realization of the morpheme and/or (in the case of wh- questions) interaction with information structure. Under this second account, the yes-no questions might be thought of as a 'pure' case, untainted by the balance between given-new information that wh-in-situ questions encode. Here we outline what this account would entail, since it not only allows us to maintain C\&R's proposal that wh-in-situ and yes-no questions share the same morpheme, but also to lay out the role of information structure.

As we noted above, givenness has been argued to play a central role in wh-in-situ questions. We have reasons to think that it may have also played a role in our experimental studies. While both wh-in-situ and yes-no questions in our study had a rising contour, it is possible that the de-stressing of given information 
(something we specifically manipulated in the contexts preceding out target sentences to make them felicitous) contrasted with the focus requirement on the question term, resulted in a more depressed rising contour for the wh-in-situ questions, as compared with their yes-no counterparts.

In recent work exploring the interaction of information structure and syntax in Czech, Kučerová $(2007,2008)$ proposes that givenness is linked to an operator (her G-operator), which can be inserted at any place in the sentence structure. From its insertion position, the operator propagates giveness marking up the structure until the edge of a domain. The effect of this G-operator, then, is to divide the sentence structure into two distinct domains such that all material marked as given precedes all new information, as illustrated here in Example (10) (Kučerová (2007:357)):

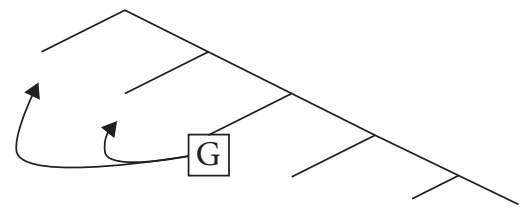

If the G-operator is inserted in a point low in a structure (e.g. on the object), then everything preceding is marked as given, with the semantic consequence that unless discourse conditions are met for this marking, a presupposition failure ensues. Presupposition failure can be avoided, Kučerová proposes, if the givenmarked object is moved to the beginning of the sentence so that as a result, nothing else occurs in the scope of the G-operator. Kučerová $(2007,2008)$ argues that this movement happens in Czech, where topicalized or given constituents must always move to a sentence-initial position. That the given-new contrast can be captured through movement was previously proposed by Wagner $(2005,2006)$, who argued that giveness-movement is motivated whenever independent prosodic constraints interfere with the de-stressing of given material.

Returning to French wh-in-situ questions, let us see how the givenness marking we have just discussed and the information structure constraints discussed by Hamlaoui, could account for our results, while still maintaining C\&R's proposed intonation morpheme. Recall that $\mathrm{C} \& \mathrm{R}$ assume that the intonation morpheme is merged in an initial $\mathrm{C}$, but its prosodic effect targets the end of the sentence. One explanation for this is that the morpheme is an $\mathrm{H}$ underspecified in terms of its docking position: it can target a prominent position in the material that follows (such as the focused wh-element), resulting in an $\mathrm{H}^{*}$ on the corresponding syllable, or it can dock on a sentence-final position, resulting in H\% (a high boundary tone). We develop this account in DS\&K. Another possibility, however, is that the effect is local and does not target the sentence terminus long distance. How, then, could this be, if $\mathrm{C}$ in French is sentence-initial, and the rising is observed sentence-finally? We would like to entertain the possibility that in these sentences, 
for reasons of movement due to givenness, the $\mathrm{C}$ actually becomes sentence-final. Let us see how this analysis would proceed.

Recall that as proposed by Hamlaoui, the wh-term in the French in-situ question is the only new element of the clause. Following Kučerová, the G-operator should thus be inserted right before the wh-term, with the result that everything preceding this term would be marked as given. Now, this G-marking would satisfy Hamlaoui's proposal that the whole non-wh portion of the clause be marked as given only when the $w h$-term is the last element in the clause. Yet, although there seems to be a general tendency for the question term to occupy a sentence final position in French in-situ questions, a final position is nevertheless not always required, and sometimes even disfavored. For Example, (9) above becomes odd if, as in (11), the wh-in-situ term is in final position, even if the time adverbial expression is contextually given. ${ }^{4}$

*Vous faites ce soir quoi?
you.PL do-PRs.2PL this evening what
'What are you doing tonight?'

4. Hamlaoui (2008) claims that all material that comes after the wh-expression must be dislocated. Here, we provide evidence, using subject pronoun doubling, that questions this claim. Being right dislocated, doubling pronouns reliably mark the prosodic boundary of a sentence domain. With doubling, an in-situ question like (9a) (Vous faites quoi ce soir? 'You're doing what tonight?') can be realized in two distinct ways: with the time adverbial dislocated (ce soir) after the doubled pronoun, as in (i), or with no adverbial dislocation as in (ii). In (ii), since the material that follows the $w h$ precedes the doubling pronoun, it is within the sentence prosodic domain:

(i) Vous faites quoi, vous, $\underline{c^{\prime}}$ soir? you.PL do-PRs.2PL what you.PL this evening 'You do what, you, tonight?'

(ii) Vous faites quoi c' soir, vous? you.PL do-PRs.2PL what this evening you.PL 'You do what tonight, you?'

And this is clearly the only possible order. Indeed, forcing the wh to occur at the edge of sentence prosodic domain as in (iii) remains as impossible as in (11) in the text. This shows that there are clear cases, i.e (ii) and (11), in which the in-situ-wh is non-final, and where the material that follows occurs inside the sentence prosodic main domain and is not dislocated.

$$
\begin{aligned}
& \text { (iii) *Vous faites c' soir quoi, vous? } \\
& \text { you.PL do-Prs.2PL this evening what you.PL } \\
& \text { 'You do tonight what, you?' }
\end{aligned}
$$

Further addressing the role of dislocation deserves careful experimental investigation that we leave to future research. 
Yet the requirement that the wh-in-situ term occupies a sentence-final position appears to be present in other languages. Uribe-Etxebarria (2003), for example, claims that in the case of wh-in-situ questions in Spanish, the wh-term is syntactically required to occupy a sentence-final position. This situation, she argues, is achieved as the result of two consecutive movements: wh-movement to Spec, CP for checking purposes, followed by further leftward movement of the TP remnant to a position preceding CP. Consistent with Kučerovás account, Uribe-Etxebarria argues that TP movement in Spanish in-situ questions is information driven - a sort of clause topicalization that is linked to its presupposed or given interpretation.

Returning to French in-situ questions, we adapt Uribe-Extebarria's TP movement idea, but with Spec, CP at its target, and do not enforce the syntactic movement of the wh-term. Suppose that to mark the clause as given, Kučerovás G-operator were to be inserted in $\mathrm{C}$, prompting in turn the information-driven movement of the whole complement TP to Spec, $\mathrm{CP}$ for givenness marking. The intonation morpheme (also in C) would now in effect occupy a sentence-final position actually allowing the rise it dictates to manifest itself right where the morpheme is (i.e. at the end of the sentence). ${ }^{5}$ Thus TP movement in such cases satisfies both the information requirement on the clause interpretation and locality restrictions on the effects of the $\mathrm{H}$ morpheme.

What this analysis leaves out so far, however, is what happens with the whterm. Remaining in the clause, it would now also be marked as given if nothing else happened. Moving it to Spec, $\mathrm{CP}$ - as Uribe-Etxebarria proposed, could satisfy syntax and focus marking, but this is now impossible, if as suggested here, Spec, $\mathrm{CP}$ is occupied by the leftward moved TP. On this view, then, we can see $w h$-in-situ questions as illustrating an information structure tension between the necessity to mark the containing clause as given (involving movement of TP to Spec, $\mathrm{CP}$ ) on the one hand, and on the other hand, the necessity to mark the wh-term for focus.

Here, we would like to suggest a resolution of this tension based on recent work by Richards $(2006,2010)$. Motivated by Japanese data, Richards has claimed that there is a way to satisfy both the information requirement on a wh-term and the unique syntactic dependency it forms with an interrogative $\mathrm{C}$ by allowing the wh-term and $\mathrm{C}$ to form the boundary of a prosodic domain, i.e. what Richard (2010) terms a wh-domain. In this domain, no relevant prosodic boundaries can intervene between the $w h$-term and the C. Richard argues that in Japanese, since

5. This proposal in effect suggests that C\&R's intonation morpheme encodes something like Kučerovás G-operator and question force. This interpretation may also work for purely intonation yes-no questions, if - as C\&R conjectured - these questions also occur in contexts involving presupposition or givenness. 
$\mathrm{C}$ is clause-final, this requirement is manifested by pitch compression between the wh-term and the final C. Adapting this idea to the case under discussion, we suggest that for French in-situ questions, a prosodic wh-domain is also formed between the wh-term and the $\mathrm{C}$ which is now sentence-final, after the information-driven movement of TP to Spec, CP. ${ }^{6}$ If encoded by pitch compression, as in Japanese, this proposal would predict both a depressed rise for French in-situ questions as compared to yes-no questions (a result of pitch compression between the wh- element and C) and the correlation between the pitch accent on the wh-term (a) realization of focus) and the sentence-final rise.

Recall that our experimental findings indeed revealed a pitch compression effect beginning after the $w h$-term and terminating at the end of the sentence. (An analysis of sentence-initial region preceding the wh-term revealed a plateau for both groups.) Furthermore, the rise mandated by C\&R's intonation morpheme is more compressed in wh-in-situ questions as compared to yes-no questions. Finally, the distinction between the two groups, instead of questioning the obligatory nature of C\&R's morpheme appears to encode a correlated variability in the phonetic realization of the relation between the focused in-situ wh term and the rising morpheme in $\mathrm{C}$ : the stronger the focus, the more compressed the rise and vice-versa. This, we suggest, manifests speaker variability in the realization of the wh-domain. Our proposed analysis can therefore be represented in (12), where C hosts both the intonation morpheme (Q) and the Givenness Operator (G), which triggers movement of the TP ('She put which shape in the middle?') to Spec, CP, and where the pitch compression arrow represents the realization of the prosodic domain between the wh-element and C:

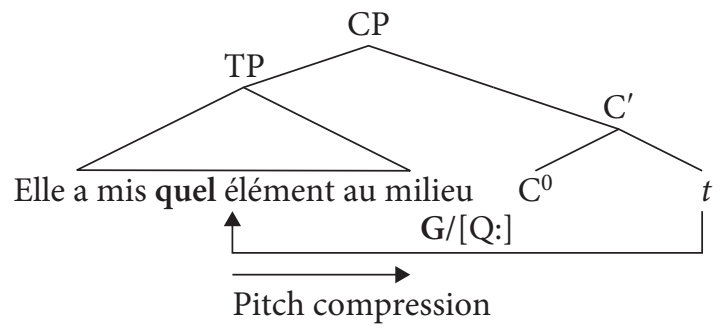

6. Although our proposal is in the spirit of Richards' framework, it does not follow it to the letter. French is a right-headed prosodic phrasing language with a clause-initial C, predicted on his view to allow wh-in-situ as an option. On our proposal, C is no longer clause-initial, as a result of TP movement. To incorporate our proposal into Richards' framework, we would have to motivate which position of $\mathrm{C}$ should be taken into account, and how the directionality of phrasing and the $\mathrm{C}$ position aligns with other languages he considered. 
The analysis we put forth in this section for French wh-in-situ questions is therefore an attempt to combine the syntactic implications of C\&R's proposal, the discourse considerations of Hamlaoui's account, the findings of our prosodic experimental investigation, and the formal implementations of movement prompted by information structure outlined by a number of other researchers. At the same time, it paints a new landscape of how syntax, prosody and information structure interact in these constructions. Our proposal allows us to maintain C\&R's proposal that the syntactic licensing of wh-in-situ questions involves a specialized morpheme in $\mathrm{C}$, while accounting for the distinction in height with yes-no questions and for the variability in the instantiation of wh-in-situ questions noted occasionally in the literature on this topic and observed quantitatively in our study. Our analysis also joins in the growing consensus that in wh-in-situ questions, the status of the non-wh-content in the discourse context must be given.

As a concluding remark, we note that our proposal also carries an account of whether or not wh-in-situ questions are allowed in a language. In contrast to moved wh- questions, wh-in-situ questions are proposed to involve structures in which TP, rather than the question term, moves to Spec, CP, following Kayne (1994). But here the movement is informationally - rather than syntactically motivated, suggesting a possible novel avenue to explain why such wh-in-situ questions cannot be embedded. Although movement of the whole clause (TP) to the Spec of an embedded C is possible for languages such as Japanese and Korean, when syntactically motivated, it is far less trivial to propose information structure motivation for such an embedded movement. For now however, we leave exploration of such consequences for future research.

\section{References}

Adli, Aria. 2006. "French wh-in-situ questions and syntactic optionality: Evidence from three data types." Zeitschrift für Sprachwissenschaft 25: 163-203.

Baunaz, Lena \& Patin, Cédric. 2009. "Prosody refers to semantic factors: Evidence from French wh- words." In Actes d'Interface Discours and Prosodie, Elisabeth Delais-Roussarie \& Hi-Yon Yoo (eds), 93-107.

Beyssade, Claire, Delais-Roussarie, Elisabeth \& Marandin, Jean-Marie. 2007. "The prosody of French interrogatives." Noveaux Cahiers de Linguistique Française 28: 163-175.

Boeckx, Cedric. 2000. "Decomposing French questions." In Proceedings of the 23rd Annual Penn Linguistics Colloquium, Jim Alexander, Na-Rae Han \& Michelle Minnick Fox (eds), 69-80. Philadelphia, PA: University of Pennsylvania Working Papers in Linguistics.

Boersma, Paul \& Weenink, David. 1999-2011. Praat: Doing phonetics by computer. [http:// www.praat.org/].

Bošcović, Źeljko. 2000. "Sometimes in SpecCP, sometimes in-situ." In Step by Step: Essays on Minimalism in Honor of Howard Lasnik, Roger Martin, David Michaels, \& Juan Uriagereka (eds), 53-87. Cambridge, Mass.: MIT Press. 
Cheng, Lisa. 1997. Wh-in-Situ Phenomena in French. Master's thesis, University of British Columbia.

Cheng, Lisa Lai-Shen \& Rooryk, Johan. 2000. "Licensing wh-in-situ." Syntax 3: 1-19.

Coveney, Aidan. 1995. "The use of the QU-final interrogative structure in spoken French." Journal of French Language Studies 5: 143-171.

Delattre, Pierre. 1966. "Les dix intonations de base du Français." The French Review 40: 1-14.

Déprez, Viviane, Syrett, Kristen \& Shigeto Kawahara. 2012. "The interaction of syntax, prosody, and discourse in licensing French wh-in-situ questions." Lingua.

Féry, Caroline \& Samek-Lodovici, Vieri. 2006. "Focus projection and prosodic prominence in nested foci." Language 82: 131-150.

Hamlaoui, Fatima. 2009. La Focalisation à L'interface de la Syntaxe et de la Phonologie: le Cas du Français dans une Perspective Typologique. Ph.D. dissertation, Université Paris III Sorbonne Nouvelle.

Hamlaoui, Fatima. 2010. "On the role of phonology and discourse in Francilian French wh-questions. Journal of Linguistics 47: 1-34.

Kayne, Richard S. 1994. The Antisymmetry of Syntax. Linguistic Inquiry Monograph Twenty-Five. Cambridge, MA: MIT Press.

Kučerová, Ivona. 2007. The Syntax of Givenness. Ph.D. dissertation, MIT.

Kučerová, Ivona. 2008. "Givenness and maximize presupposition." In Proceedings of Sinn und Bedeutung 12, Atle Grønn (ed.), 353-366. Oslo: ISLO.

Mathieu, Éric. 2009. "Les questions en Français: Micro et macro-variation." In Le Français d'Ici: Études Linguistiques et Sociolinguistiques de la Variation, France Martineau, Raymond Mougeon, Terry Nadasdi \& Mireille Tremblay. 37-66. Toronto: GREF.

Richards, Norvin. 2006. "Beyond strength and weakness." Ms. MIT.

Richards, Norvin. 2010. Uttering Trees. Cambridge, MA: MIT Press.

Schwarzschild, Roger. 1999. "GIVENness, AvoidF and other constraints on the Placement of Accent." Natural Language Semantics 7: 141-177.

Starke, Michal. 2001. Move dissolves into Merge: A Theory of Locality. Ph.D. dissertation, University of Geneva.

Vergnaud, Jean-Roger \& Zubizarreta, Maria Luisa. 2001. "The logical structure of informational and contrastive questions." Paper presented at Université Paris 8.

Uribe-Etxebarria, Myriam. 2003. "In situ questions and masked movement." Linguistic Variation Yearbook 2: 217-257.

Wagner, Michael. 2005. Prosody and Recursion. Ph.D. dissertation, MIT.

Wagner, Michael. 2006. "Givenness and locality." In Proceedings of SALT XVI, Masayuki Gibson \& Jonathan Howell (eds), 295-312. Ithaca, NY: CLC Publications.

Williams, Edwin. 1997. "Blocking and anaphora." Linguistic Inquiry 28: 577-628.

Wunderli, Peter. 1983. "L'Intonation des interrogatives du type, 'Il est né en quelle année?" Romanica Gandensia 20: 169-181.

Wunderli, Peter. 1984. "L'intonation des questions sans marquée segmentale." In Travaux de Linguistique et de Litterature, Le Centre de Philologie et de Litteratures Romanes de l'Université de Strasbourg (ed.), 203-250. Strasbourg, France.

Zubizarreta, Maria Luisa. 2003. "Intervention effects in the French wh-in-situ construction: Syntax or interpretation?” In A Romance Perspective in Language Knowledge and Use, Rafael Nunes-Cedeno, Luis Lopez \& Richard Cameron (eds), 359-380. Selected Papers from the 31st Symposium on Romance Languages. Amsterdam/Philadephia, PA: John Benjamins. 
